\title{
Effect of the High Frequency Chest Wall Oscillation (HFCWO) on Pulmonary Function and Walking Ability in Stroke Patients
}

\author{
Beom-Ryong Kim', Jin Park² \\ 'Department of Physical Therapy, The Graduate School, Sahmyook University, Seoul; ${ }^{2}$ Department of Physical Therapy, The Graduate School, Daegu \\ University, Daegu, Korea
}

Purpose: This investigation aimed to determine the effects of treadmill training (T) and high frequency chest wall oscillation (HFCWO) on pulmonary function and walking ability in stroke patients as well as propose an exercise program to improve cardiovascular function. Methods: Twenty hemiplegic stroke patients were randomized to either the control group (CG) $(n=10)$ or the experimental group (EG), which received $\Pi$ and HFCWO $(n=10)$. Pulmonary function was quantitated using patient forced vital capacity $(F V C)$ and forced expiratory volume at one second (FEV1) while walking speed was assessed by the $10 \mathrm{~m}$ walking test (10MWT). Further, walking endurance was determined utilizing the 6-minute walk test (6MWT). Subjects of the EG performed the study protocol for 60 minutes, five times a week for six weeks; CG patients did not participate in regular exercise. To determine significance for the differences observed before and after exercise, within-group and between-group comparisons were conducted utilizing paired and independent t-tests, respectively, with the level of significance set at $\alpha=0.05$.

Results: Within-groups, significant differences were observed in both FVC and FEV1 $(p<0.01)$ following completion of the study protocol. Further, between-group comparisons demonstrated significant differences in both FVC $(p<0.05)$ and FEV1 $(p<0.01)$. Post-exercise, significant changes in the 10MWT and 6MWT score were observed between the EG and CG $(p<0.01)$. Further, statistically significant differences were observed in 6MWT scores between-groups $(p<0.05)$.

Conclusion: The $\Pi$ and HFCWO effectively improved pulmonary function and walking ability in subjects with stroke. The proposed program can be applied to stroke patients as a useful therapy.

Keywords: HFCWO, Pulmonary function, Stroke, Treadmill, Walking ability

\section{서 론}

뇌졸중(stroke)은 정상적인 뇌의 혈액순환의 문제로 산소공급이차단 되어 발생하며, 손상부위와 정도에 따라 호흡, 연하, 대소변, 의식, 인 지, 언어 장애 등 다양한 증상을 보인다. 특히 호흡기능의 장애로 인 공기도를 유지하기 위해 기도삽관이나 기관절개술을 시행한 환자들 은 객담의 비정상적인 증가로 폐렴이나 호흡곤란 등의 합병증으로 운동능력이 저하된다. ${ }^{2}$

뇌졸중 환자의 운동능력의 장애는 활동량을 급격하게 감소시켜 유산소능력과 폐 기능의 저하를 초래한다. 이런 문제점을 해결하기 위해 환자들에게 폐 기능을 향상시키기 위한 중재프로그램이 요구 되며, 기도 내 분비물의 배출을 돕기 위한 방법으로 기도청결기법 (airway clearance technique, ACT)들이 있다. 이들 기법 중 기관지에 정

Received Feb 19, 2017 Revised Apr 21, 2017

Accepted Apr 30, 2017

Corresponding author Beom-Ryong Kim

E-mail kimbr21@hanmail.net
체된 분비물에 중력과 물리적 힘을 이용한 체위배액, 가슴부 타진법 과 진동법 등을 적용하여 분비물을 제거해주는 중재방법으로 가슴 부물리치료(chest physiotherapy)가 있다. ${ }^{4}$ 하지만 이미 전통적인 호흡 물리치료 방법이 되었고, 최근에는 유럽에서 많이 사용되는 강제호 기기법(forced expiratory technique, FET)의 허핑(huffing), 능동순환호 흡기법(active cycle of breathing technique, ACBT), 자가배출법(autogenic drainage, $\mathrm{AD}$ ), 호기양압 마스크(PEP mask), 플루터(flutter), 고빈도가 슴벽진동(high frequency chest wall oscillation, HFCWO)등이 있다.5.8

최근 우리나라 물리치료실에서는 뇌졸중 환자를 대상으로 전통적 인 가슴부물리치료가 아닌 고빈도가슴벽진동이라는 기도청결기법 을 적용하기 시작했다. 고빈도가슴벽진동은 환자에게 공기진동발생 기와 연결된 조끼를 착용시킨 후 공기를 빠르게 넣어주고 빼주면서 가슴벽에 진동을 발생시켜 기관지의 객담을 제거하는 방법이다. ${ }^{9}$ 고 
빈도가슴벽진동은 가슴벽의 진동으로 폐 엽의 분비물을 기관지로 이동시키는 날숨기류를 만들어 낮은 폐 용량에서 일시적인 기류의 증가로 점액을 이동시키는 공기-액체 상호작용을 향상시켜 점성을 감소시킴으로써 분비물의 배출을 용이하게 만든다. ${ }^{10}$

지금까지 고빈도가슴벽진동에 대한 연구를 살펴보면, 낭포성 섬 유증 환자에게 적용하여 객담 배출과 폐 기능 향상에 효과가 있었다 는 연구," 근위축성 축삭경화증 환자에게 적용이 약화된 호흡근에 의한 폐활량의 감소와 호흡곤란발생을 완화 시킨다는 연구, ${ }^{12}$ 가슴 부외상 환자에게 적용하여 기침능력과 호흡능력이 향상되었다는 연 구, 척수손상, 다발성경화증, 운동신경원 질환의 환자들에게 적용하 여 객담배출과 폐 기능 향상에 영향을 미친다는 연구가 있다.13

이와 같이 고빈도가슴벽진동을 통해 호흡기능의 장애를 가진 다 양한 환자들을 대상으로 객담배출 향상, 호흡곤란의 완화와 폐 기능 의 향상에 효과적이라는 연구들이 보고되고 있지만, 뇌졸중 환자들 에게 고빈도가슴벽진동을 적용하여 폐 기능과 보행능력의 변화에 효과가 있는지를 비교한 연구는 미비한 실정이다. 따라서 본 연구에 서는 뇌졸중 환자들에게 고빈도가슴벽진동과 트레드밀 훈련을 실시 하여 폐 기능과 보행능력의 변화를 알아보고 최종적으로는 뇌졸중 환자의 기능적 증상을 개선시키고 효율적인 운동방법을 제공하는데 연구의 목적이 있다.

\section{연구 방법}

\section{1. 연구대상}

본 연구는 2015년 9월부터 10월까지 6주 동안 J시 소재 D병원에 내원 한 환자를 대상으로 실시하였다. 대상자는 뇌졸중으로 인한 편마비 를 진단받고, 1 년 이상 3 년 미만 경과한 자, 폐 질환 혹은 선천적 가슴 우리의 변형이나 갈비뼈 골절 등의 병력이 없는 자, 폐 기능 향상을 위 한 특별한 치료 또는 고빈도가슴벽진동을 받지 않았던 자, 보행 보조 도구 없이 독립적으로 $10 \mathrm{~m}$ 보행이 가능하며 ${ }^{14} 5-60$ 초안에 보행 할 수 있는 자, ${ }^{15}$ 트레드밀에서 $0.8 \mathrm{~km} / \mathrm{h}$ 의 속도를 유지할 수 있는 자 ${ }^{16}$ 를 대 상으로 연구자가 지시하는 내용을 이해하고 따를 수 있도록 간이 정 신상태 검사(mini mental state examination-Korea, MMSE-K) 점수가 24점 이상인 자를 대상으로 연구에 대한 근본 목적이나 의도의 설명 을 통해서 동의서를 받은 20 명을 대상으로 고빈도가슴벽진동과 트 레드밀 훈련을 실시한 실험군 $(\mathrm{n}=10)$ 과 브라인드(blind) 고빈도가슴 벽진동과 트레드밀 훈련을 실시한 대조군 $(\mathrm{n}=10)$ 으로 무작위 배정하 였다. 연구대상자 일반적인 특성은 다음과 같다(Table 1).

\section{2. 중재방법}

실험군과 대조군은 고빈도가슴벽진동 30 분, 트레드밀 훈련 30 분으
Table 1. Characteristics of participants $(n=20)$

\begin{tabular}{lccc}
\hline & $\begin{array}{c}\text { Experimental } \\
\text { group }(\mathrm{n}=10)\end{array}$ & $\begin{array}{c}\text { Control group } \\
(\mathrm{n}=10)\end{array}$ & $\mathrm{p}$ \\
\hline Sex (male/female) & $5-5$ & $4-6$ & 1.00 \\
Side of stroke (right/left) & $7-3$ & $6-4$ & 1.00 \\
$\begin{array}{l}\text { Type of stroke } \\
\text { (hemorrhage/infarction) }\end{array}$ & $2-8$ & $3-7$ & 1.00 \\
Time after stroke (month) & $18.10(6.77)^{\mathrm{a}}$ & $16.10(3.28)$ & 0.05 \\
Age (year) & $55.20(6.66)$ & $60.00(7.47)$ & 0.20 \\
Height (cm) & $163.50(8.72)$ & $157.70(11.74)$ & 0.28 \\
Weight (kg) & $66.00(10.83)$ & $62.30(6.06)$ & 0.08 \\
MMSE (scores) & $26.80(2.15)$ & $25.90(2.51)$ & 0.15 \\
\hline
\end{tabular}

${ }^{a}$ Mean (SD).

로 구성 주 5 일 6주간 시행하였으며, 대조군은 환자에게 조끼를 착용 시킨 후 공기진동발생기와 연결 부위를 분리하여 적용, 고빈도가슴 벽진동을 브라인드 하였다. 유산소훈련을 위하여 트레드밀을 이용하 였으며, 운동강도는 심박수측정기(Polar electro, Kempele, Finland)를 이용 심박수 변화량 측정 $50-70 \% \mathrm{HRmax}$ 와 $\mathrm{Borg}^{17}$ 의 운동자각도(rating of perceived wxertion, RPE)를 설정하여 운동자각도 11-15강도로 실시하였다. 고빈도가슴벽진동의 적용 시간은 30 분으로 $10 \mathrm{~Hz}, 13 \mathrm{~Hz}$, $15 \mathrm{~Hz}$ 로 점진적으로 세 가지 주파수에서 순서대로 8 분 적용 후 2 분 휴식 방법으로 하였다.1 각각 휴식시간에는 허프(huff) 또는 기침 (cough)을 통하여 기관지 분비물을 배출시켰다.

\section{3. 측정항목 및 방법}

1) 폐 기능 검사

폐 기능(pulmonary function) 측정은 폐 기능검사기(Schiller SP-260, Medical Supply Co., Ltd, Switzerland)를 사용하였다. 측정방법은 대상 자에게 검사방법에 대한 충분한 설명과 측정시범을 통하여 충분한 교육이 이루어진 상태에서 검사를 실시하였다. 측정지표는 최대 노력 성 날숨에서 얻어진 노력성 폐활량(forced vital capacity, FVC), 최대 노 력성 날숨을 시작한 후 1 초간 내쉰 1초간 노력성 날숨량(forced expiratory volume at one second, $\mathrm{FEVl}$ )을 측정하였다. 각각 폐 기능 측정은 앉은자세에서 3 회 반복 측정하여 평균값을 기록하였다.

\section{2) 보행능력 검사 \\ (1) 보행속도 검사}

$10 \mathrm{~m}$ 보행 검사 $(10 \mathrm{~m}$ walking test, $10 \mathrm{MWT})$ 는 직선 보행능력을 측정하 기 위한 검사도구로 보편적으로 신경학적 손상 환자의 보행속도 검 사에 사용되며, ${ }^{19}$ 발병 후 6 개월이 경과한 뇌졸중 환자에서 보행속도 를 측정하는데 유용한 검사도구이다. 측정방법은 총 $14 \mathrm{~m}$ 을 걷게 하 여 시작과 끝 지점의 가속과 감속 구간 $2 \mathrm{~m}$ 을 제외한 $10 \mathrm{~m}$ 을 걷는 동 안 소요된 시간을 스톱워치를 이용하여 측정하는 방법으로 3 회 반 
복 측정하여 평균시간을 기록하였다. ${ }^{20}$ 검사 재검사 간 신뢰도는 $\mathrm{r}=0.89-1.00$ 로 신뢰도가 높은 도구이다. ${ }^{21}$

\section{(2) 보행지구력 검사}

6분 보행 검사(6-minute walk test, $6 \mathrm{MWT})$ 은 보행지구력을 측정하기 위한 검사도구로 ${ }^{22}$ 신경학적 손상 환자, 심호흡계 환자 등 다양한 환 자들의 보행지구력을 검사하는데 사용된다. ${ }^{23}$ 측정방법은 대상자에 게 $\operatorname{Borg}^{17}$ 의 운동자각도를 설명하고, 운동자각도 11-15강도로 6분 동 안 가능한 가장 많은 거리를 걸을 수 있도록 교육하였으며, 검사자는 운동자각도 체크와 객관적 검사를 위하여 매 분마다 시간 경과를 알 려주면서 보행한 총 거리를 측정하였다. 검사 재검사 간 신뢰도는 $\mathrm{r}=0.97-0.99$ 로 신뢰도가 높은 도구이다. ${ }^{24}$

\section{3) 검사자}

검사자는 대한심장호흡물리치료학회(Korean academy of cardiorespiratory physical therapy, KACRPT)에서 주최하는 교육프로그램을 고급 과정(advance course)까지 이수하여 심장호흡 관련 질환에 대한 평가 와 중재방법에 대한 전반적인 지식을 갖춘 치료사가 진행하였다.

\section{4. 자료처리}

본 연구에서 얻은 자료는 윈도우용 SPSS version 18.0 (SPSS Inc., Chicago, USA)을 이용하여 분석하였다. 연구대상자들에 대한 자료는 평균 \pm 표준편차로 표시하였다. 두 군 간의 성별, 마비 측, 발병유형과 같은 연구대상자들의 비율의 차이를 알아보기 위해 빈도분석을 사용하였 고, 나이, 키, 몸무게, MMSE-K와 유병기간과 같은 연구대상자들의 일 반적인 특성을 파악하기 위해 기술통계를 사용하였다. 연구대상자 의 일반적인 특성을 Shapiro-wilk로 정규성 검정을 하였고, 실험군과 대조군의 중재 전과 후에 따른 차이를 비교하기 위하여 대응표본 t검정(Paired t-test)을 하였으며, 실험군과 대조군의 중재 전과 후 변화 량에 따른 차이를 알아보기 위하여 독립표본 t-검정(Independent ttest)을 하였다. 모든 통계학적 유의수준은 $\alpha=0.05$ 로 설정하였다.

\section{결 과}

\section{1. 폐 기능 변화 비교}

집단 내 노력성 폐활량(FVC)과 1초간 노력성 날숨량(FEV1)의 변화는 실험군과 대조군 모두에서 유의한차이가 있었다 $(\mathrm{p}<0.01)$. 집단 간 중 재 전과 후 변화량에 따른 노력성 폐활량(FVC)의 변화에서 실험군과 대조군 사이에서 유의한 차이가 있었고 $(\mathrm{p}<0.05 ; 95 \% \mathrm{CI}, 0.54-0.03), 1$ 초간 노력성 날숨량(FEV1)의 변화에서도 실험군과 대조군 사이에서 유의한 차이가 있었다 $(\mathrm{p}<0.01,95 \% \mathrm{CI}, 0.58-0.18)$ (Table 2).

\section{2. 보행능력 변화 비교}

집단 내 보행속도(10MWT)와 보행지구력(6MWT)의 변화는 실험군 과 대조군 모두에서 유의한 차이가 있었다 $(\mathrm{p}<0.01)$. 집단 간 중재 전 과 후 변화량에 따른 보행속도(10MWT)의 변화에서 실험군과 대조 군 사이에서 유의한 차이가 없었고, 보행지구력(6MWT)의 변화에서 실험군과 대조군 사이에서 유의한 차이가 있었다 $(\mathrm{p}<0.05,95 \% \mathrm{CI}$, 20.37-1.63) (Table 2).

\section{고 찰}

본 연구는 뇌졸중 환자의 폐 기능 및 보행능력을 향상시키기 위한 중 재방법으로 주 5일 6주간 고빈도가슴벽진동과 트레드밀 훈련 적용 이 폐 기능(FVC, FEV1)과 보행능력(6MWT, 10MWT)에 어떠한 영향 을 미치는지 논의하고자 한다.

고빈도가슴벽진동은 기존의 가슴부물리치료와 다르게 치료사의 시간과 노동을 감소시켜주며, ${ }^{25}$ 고빈도가슴벽진동을 환자들에게 적 용한 결과 $84 \%$ 가 중재 중 불편감을 느낄 수 없었으며, 가슴부물리치 료와 비교하여 $50 \%$ 의 환자가 고빈도가슴벽진동을 더 선호하였다. ${ }^{26}$ 이와 같이 고빈도가슴벽진동은 치료사의 적절한 도움으로 환자가 손쉽게 할 수 있으며 부작용이 거의 없는 중재방법이다. ${ }^{27}$

본 연구에서 고빈도가슴벽진동과 트레드밀 훈련을 실시한 실험군에 서 FVC와 FEV1는 중재 전보다 후에 유의하게 개선되었으며 $(\mathrm{p}<0.01)$, 집

Table 2. Outcome measurements $(n=20)$

\begin{tabular}{|c|c|c|c|c|c|c|c|}
\hline \multirow{2}{*}{ Variables } & \multicolumn{3}{|c|}{ Experimental group $(n=10)$} & \multicolumn{3}{|c|}{ Control group $(n=10)$} & \multirow{2}{*}{$\begin{array}{c}\text { Between groups } \\
\text { p-values }(95 \% \mathrm{Cl})\end{array}$} \\
\hline & Pre-test & Post-test & Post-Pre & Pre-test & Post-test & Post-Pre & \\
\hline FVC (L) & $2.31(0.83)^{a}$ & $2.77(0.79)^{*}$ & $0.46(0.38)^{+}$ & $2.36(0.81)$ & $2.53(0.82)^{*}$ & $0.17(0.08)$ & $0.03^{* \star}(0.54-0.03)$ \\
\hline FEV1 (L) & $1.87(0.61)$ & $2.32(0.65)^{\star}$ & $0.45(0.29)^{+}$ & $2.05(0.70)$ & $2.12(0.70)^{\star}$ & $0.06(0.05)$ & $0.01^{\star \star \star}(0.58-0.18)$ \\
\hline 10MWT (sec) & $14.62(7.36)$ & $12.52(7.17)^{\star}$ & $2.10(0.46)$ & $18.73(10.09)$ & $16.60(9.37)^{\star}$ & $2.13(1.06)$ & $0.93(0.80-0.74)$ \\
\hline 6MWT (m) & 253.50 (112.99) & $278.50(116.36)^{*}$ & $25.00(11.30)^{+}$ & $236.00(123.06)$ & $250.00(119.19)^{*}$ & $14.00(8.43)$ & $0.02^{* *}(20.37-1.63)$ \\
\hline
\end{tabular}

${ }^{a}$ Means (SD), * significant difference within groups, 'Significant difference between group.

FVC: forced vital capacity, FEV1: forced expiratory volume at one second, 6MWT: 6-minutes walking test, 10MWT: $10 \mathrm{~m}$ walking test.

${ }^{* *} \mathrm{p}<0.05,{ }^{* * *} \mathrm{p}<0.01$ 
단 간 FVC와 FEV1의 중재 전과 후 변화량 비교에서 대조군에 비해 실험군에서 유의한 차이를 얻었다 $(\mathrm{p}<0.05, \mathrm{p}<0.01)$. 이러한 결과는 기 도 내 객담이 고빈도가슴벽진동의 반복적인 진동을 통해 점도가 감 소되어 기도 벽에서 분리된 분비물이 공기-액체의 상호작용으로 움 직임이 증가하여 체외로 배출되어 호흡근육의 효율성을 증가시킨 결 과이며, ${ }^{28}$ 반복적인 진동은 들숨 시 가슴우리에 빠른 팽창과 수축으 로 감소된 폐 용적에 공기의 유량을 증가시켜 FVC, FEV1을 증가할 수 있도록 도와준 결과로 보인다. ${ }^{29} \mathrm{Nicolini}$ 등 ${ }^{30}$ 은 기관지 확장증 환자 30 명을 대상으로 10 명씩 고빈도가슴벽진동군, 전통적인 가슴부물리 치료군, 대조군으로 무작위 배정하여 하루 2 회 15 일 동안 30 회 중재 한 결과 고빈도가슴벽진동을 실시한 실험군에서 폐 기능(FVC, $\mathrm{FEV1}$ 과 삶의 질에서 유의한 향상을 보였고, Park 드이은 비소세포성 폐암 환자 66명을 대상으로 고빈도가슴벽진동을 실시한 실험군과 가슴부물리치료를 실시한 대조군으로 배정하여 중재한 결과 고빈도 가슴벽진동을 실시한 실험군에서 FEV1과 산소포화도에서 유의한 향상을 보였으며, Kang 등 32 은 뇌졸중으로 인한 편마비 환자 20명을 대상으로 10 명씩 무작위배정하여 일반적인 운동치료와 호흡운동을 주 5 회 6 주간 중재한 결과 호흡운동을 실시한 실험군에서 집단 내. 간 $\mathrm{FVC}, \mathrm{FEV} 1$ 에서 유의한 향상을 보였다. 또한, $\mathrm{Kim}^{33}$ 은 뇌졸중 환자 54 명을 대상으로 가슴우리확장운동군, 유산소운동군, 대조군으로 무작위배정하여 주 5 일 4 주간 중재한 결과 두 운동군에서 집단 내. 간 FVC, FEV1에서 유의한 향상을 얻었으며 두 가지 형태의 중재방법 을 재활환자에 있어서 서로 보완적 방법으로 유용하게 사용될 수 있 다고 하였으며, 본 연구의 고빈도가슴벽진동과 트레드밀 훈련의 적절 성을 뒷받침해준다. 위와 같은 연구들은 대상자, 중재 빈도에는 차이 가 있지만 가슴우리에 대한 중재가 가슴우리의 움직임을 증가시켜 폐 용적에 영향 미쳐 $\mathrm{FVC}, \mathrm{FEV1}$ 의 향상 시켰으며 본 연구의 중재방법 의 효율성을 뒷받침 해준다.

본 연구에서 고빈도가슴벽진동과 트레드밀 훈련이 보행능력 향상 에 미치는 영향을 알아보기 위하여 보행속도검사로 $10 \mathrm{MWT}$ 를 보행 지구력검사로 $6 \mathrm{MWT}$ 를 실시하였다. 그 결과 중재 전과 후 실험군과 대조군 모두 10MWT와 6MWT에서 유의한 차이가 있었다 $(\mathrm{p}<0.01)$. 하지만 두 군간 비교에서 $10 \mathrm{MWT}$ 에서는 유의한 차이가 없었지만 $6 \mathrm{MWT}$ 에서는 유의한 차이가 있었다 $(\mathrm{p}<0.05)$. 이러한 결과는 Kim과 $\mathrm{Shin}^{34}$ 이 뇌졸중 환자 18 명을 대상으로 주 3 회 4 주 동안 호흡근육 강 화 운동을 실시한 결과 폐 기능과 $6 \mathrm{MWT}$ 에서 유의한 향상을 보였지 만 10MWT에서는 그룹 간 유의한 차이가 없었는데 이는 보행속도 능 력이 보행지구력 능력보다 오히려 신경운동조절에 주로 영향을 받는 결과로 생각되며, 본 연구의 결과를 뒷받침해준다. 또한 본 연구에서 고빈도가슴벽진동을 통해서 얻어진 $6 \mathrm{MWT}$ 의 거리 증가는 $\mathrm{FVC}$, $\mathrm{FEV} 1$ 과 같은 폐 기능의 향상을 통해서 보행지구력이 향상되었음을
보여주며, Macko 등 35 이 만성 뇌졸중 환자를 대상으로 트레드밀을 이 용한 유산소운동 훈련이 뇌졸중 환자의 폐 기능의 향상을 가져왔으 며 그로 인해 보행지구력이 증가되는 결과를 얻었으며, 본 연구의 결 과와 일치한다. 이러한 결과들로 볼 때 보행이 가능한 뇌졸중 환자 일 지라도 트레드밀 형태의 유산소훈련만을 실시한 것보다는 고빈도가 슴벽진동을 병행하여 실시할 경우 폐 기능과 보행지구력의 향상된 결과로 볼 때 보행이 가능한 뇌졸중 환자에게 필요한 중재방법이라 생각된다.

이상의 연구를 종합해보면 실험군과 대조군 모두에서 폐 기능의 지표인 FVC와 FEV1, 보행능력의 지표인 6MWT와 $10 \mathrm{MWT}$ 의 변수들 이 중재 후에 유의하게 향상되었으며, 중재 전과 후 변화량 차이는 폐 기능의 지표인 FVC와 FEV1, 보행능력의 지표인 6MWT의 변수에서 대조군에 비해 실험군에서 유의한 차이가 나타났다. 이와 같은 결과 는 고빈도가슴벽진동이 폐 기능과 보행지구력을 증진시키는데 효과 가 있으며, 고빈도가슴벽진동과 트레드밀 훈련이 물리치료실에서 시 행하여야 할 필요가 있다고 사료된다. 반면 본 연구의 제한점은 연구 대상자 수가 적다는 것과 보행이 가능한 뇌졸중 환자만을 대상으로 했기 때문에 모든 뇌졸중 환자에게 일반화시키기에는 어려움이 있 다는 점이다.

폐 기능과 보행능력은 뇌졸중 환자의 재활에 중요하며, 뇌졸중 환 자에게서 보행능력은 일상생활에서 가장 필요한 기본적인 기능이다. 또한 폐 기능은 일상생활활동을 수행하는데 필수적인 요소이다. ${ }^{36}$ 따라서 폐 기능의 향상은 보행을 개선시키기 위한 중요한 인자가 될 수 있을 것으로 생각되며, 뇌졸중 환자의 폐 기능과 보행능력에 관계 의 입증을 위해향후 보다 다양한 연구가 필요할 것이다.

\section{참고문헌}

1. Cho KH, Kim YS, Bae HS et al. Clinical observation on the admitted patients of department of cardiac internal medicine of oriental hospital. J Kyung Hee Univ Med Cent. 1996;12(2):200-13.

2. Epstein SK. Late complications of tracheostomy. Respir Care. 2005; 50(4):542-9.

3. Kelly JO, Kilbreath SL, Davis GM et al. Cardiorespiratory fitness and walking ability in subacute stroke patients. Arch Phys Med Rehabil. 2003;84(12):1780-5.

4. Son SK. A review of literature an chest physiotherapy for application to nursing. The New Medical Journal. 1994;37(1):129-34.

5. Hasani A, Pavia D, Agnew JE et al. Regional lung clearance during cough and forced expiration technique (FET): effects of flow and viscoelasticity. Thorax. 1994;49(6):557-61.

6. McKoy NA, Saldanha IJ, Odelola OA et al. Active cycle of breathing technique for cystic fibrosis. Cochrane Database Syst Rev. 2012;12:CD007862.

7. Borka P, Gyurkovits K, Bódis J. Comparative study of PEP mask and Flutter on expectoration in cystic fibrosis patients. Acta Physiol Hung. 
2012;99(3):324-31.

8. Esguerra-Gonzales A, Ilagan-Honorio M, Kehoe P et al. Effect of highfrequency chest wall oscillation versus chest physiotherapy on lung function after lung transplant. Appl Nurs Res. 2014;27(1):59-66.

9. Anderson CA, Palmer CA, Ney AL et al. Evaluation of the safety of highfrequency chest wall oscillation (HFCWO) therapy in blunt thoracic trauma patients. J Trauma Manag Outcomes. 2008;2(1):8.

10. Tomkiewicz RP, Biviji A, King M. Effects of oscillating air flow on the rheological properties and clearability of mucous gel simulants. Biorheology. 1994;31(5):511-20.

11. Kluft J, Beker L, Castagnino M, et al. A comparison of bronchial drainage treatments in cystic fibrosis. Pediatr Pulmonol. 1996;22(4):271-4.

12. Lange DJ, Lechtzin N, Davey C, et al. High-frequency chest wall oscillation in ALS: an exploratory randomized, controlled trial. Neurology. 2006;67(6):991-7.

13. Fink JB, Mahlmeister MJ. High-frequency oscillation of the airway and chest wall. Respir Care. 2002;47(7):797-807.

14. Hase K, Suzuki E, Matsumoto M et al. Effects of therapeutic gait training using a prosthesis and a treadmill for ambulatory patients with hemiparesis. Arch Phys Med Rehabil. 2011;92(12):1961-6.

15. Pohl M, Mehrholz J, Ritschel C et al. Speed-dependent treadmill training in ambulatory hemiparetic stroke patients: a randomized controlled trial. Stroke. 2002;33(2):553-8.

16. Wada Y, Kondo I, Sonoda S et al. Preliminary trial to increase gait velocity with high speed treadmill training for patients with hemiplegia. Am J Phys Med Rehabil. 2010;89(8):683-7.

17. Borg GA. Psychophysical bases of perceived exertion. Med Sci Sports Exerc. 1982;14(5):377-81.

18. Osman LP, Roughton M, Hodson ME et al. Short-term comparative study of high frequency chest wall oscillation and European airway clearance techniques in patients with cystic fibrosis. Thorax. 2010;65(3): 196-200.

19. Deathe AB, Miller WC. The L test of functional mobility: measurement properties of a modified version of the timed "up \& go" test designed for people with lower-limb amputations. Phys Ther. 2005;85(7):626-35.

20. Dean CM, Richards CL, Malouin F. Task-related circuit training improves performance of locomotor tasks in chronic stroke: a randomized, controlled pilot trial. Arch Phys Med Rehabil. 2000;81(4):409-17.

21. Dobkin BH. Short-distance walking speed and timed walking distance: redundant measures for clinical trials? Neurology. 2006;66(4):584-6.

22. Swisher A, Goldfarb A. Use of the 6-minute walk/run test to predict peak oxygen uptake in older adults. Cardiopulm Phys Ther J. 1998;
9(3):3-5.

23. Kosak M, Smith T. Comparison of the 2-, 6-, and 12-minute walk tests in patients with stroke. J Rehabil Res Dev. 2005;42(1):103-7.

24. Fulk GD, Reynolds C, Mondal S et al. Predicting home and community walking activity in people with stroke. 2010;91(10):1582-6.

25. Woo MS. High frequency chest compression and PEP. Pediatr Pulmonol Suppl. 2004;26:152-3.

26. Allan JS, Garrity JM, Donahue DM. High-frequency chest-wall compression during the 48 hours following thoracic surgery. Respir Care. 2009;54(3):340-3.

27. Oermann CM, Sockrider MM, Giles D et al. Comparison of high-frequency chest wall oscillation and oscillating positive expiratory pressure in the home management of cystic fibrosis: a pilot study. Pediatr Pulmonol. 2001;32(5):372-7.

28. Dosman CF, Jones RL. High-frequency chest compression: a summary of the literature. Can Respir J. 2005;12(1):37-41.

29. Chatburn RL. High-frequency assisted airway clearance. Respir Care. 2007;52(9):1224-35.

30. Nicolini A, Cardini F, Landucci $\mathrm{N}$ et al. Effectiveness of treatment with high-frequency chest wall oscillation in patients with bronchiectasis. BMC Pulm Med. 2013;4(1)13-21.

31. Park H, Park J, Woo SY et al. Effect of high-frequency chest wall oscillation on pulmonary function after pulmonary lobectomy for non-small cell lung cancer. Crit Care Med. 2012;40(9):2583-9.

32. Kang JI, Kim BR, Park SK, et al. Effects of deep abdominal muscle strengthening exercises on pulmonary function and the ability to balance in stroke patients. J Kor Phys Ther. 2015;27(4):258-63.

33. Kim SD. Comparing the effects of chest expansion exercise and aerobic exercise on gait, pulmonary function, and activities of daily living in stroke patients. DaeJeon University Dissertation of Master's Degree. 2013

34. Kim JS, Shin WS. The effects of respiratory muscle strengthening training on pulmonary function and gait ability in subacute stroke patients. J Korean Soc Phys Med. 2013;8(4):489-96.

35. Macko RF, Ivey FM, Forrester LW et al. Treadmill exercise rehabilitation improves ambulatory function and cardiovascular fitness in patients with chronic stroke: a randomized, controlled trial. Stroke. 2005;36(10): 2206-11.

36. Park, GA, Hong JR. Correlation between respiratory function and performance of activities of daily living in stroke patients. J Rehebil Res. 2014;18(3):309-21. 